\title{
E-commerce Smartphone Application
}

\author{
Abdullah Saleh Alqahtani \\ School of Computer Science, Engineering and \\ Mathematics, Faculty of Science and Engineering, \\ Flinders University, \\ Adelaide SA 5001, Australia
}

\author{
Robert Goodwin \\ School of Computer Science, Engineering and \\ Mathematics, Faculty of Science and Engineering, \\ Flinders University, \\ Adelaide SA 5001, Australia
}

\begin{abstract}
Mobile and e-commerce applications are tools for accessing the Internet and for buying products and services. These applications are constantly evolving due to the high rate of technological advances being made. This paper provides a new perspective on the types of applications that can be used. It describes and analyses device requirements, provides a literature review of important aspects of mobile devices that can use such applications and the requirements of websites designed for $\mathbf{m}$ commerce. The design and security aspects of mobile devices are also investigated. As an alternative to existing m-commerce applications, this paper also investigates the characteristics and potential of the PhoneGap cross-mobile platform application. The results suggest that effective mobile applications do exist for various Smartphones, and web applications on mobile devices should be effective. PhoneGap and Spree applications can communicate using JSON instead of the XML language. Android simulators can be used for ensuring proper functionality and for compiling the applications.
\end{abstract}

Keywords- E-commerce ; PhoneGap ; M-commerce ; Smartphones ; Spree-commerce ; Ruby on Rails.

\section{INTRODUCTION}

The internet has changed many aspects of society, from business to recreation, from culture to communication and technology, as well as shopping and travelling. This new form of communication has provided new ways of doing business with the help of technological development. E-commerce is the new way of shopping and doing business. Technology has allowed companies to promote and sell their products on new markets, overcoming geographical borders as never before. Consumers have access to a wider market of products when they use wireless and internet technologies. Mobile devices with wide access to the Internet have allowed companies to reach consumers in more diverse ways, thus ensuring deep market penetration.

This study investigates the opportunities generated through mobile telephone access to the Internet [13]. Faster wireless networking standards allow wireless devices to use more ecommerce applications, and consequently, permit wider access to mobile commerce (m-commerce) [14]. M-commerce has been defined as "a special branch of e-commerce, in which mobile devices and their network connection medium are used to buy, sell, and promote products, services, and information" [20]. According to Koukia, Rigou and Sirmakessis (2006), wireless technologies have improved traditional e-commerce by "providing the additional aspects of mobility (of participation) and portability (of technology)." On this theme, mobile and e-commerce application developments are an important factor for the expansion of m-commerce among consumers. The technical characteristics of devices and corresponding applications, as well as Internet access facilities, are determining the level of acceptance of $\mathrm{m}$ commerce and its development. Aspects like processing power, display and device size, mobile internet coverage, standardization and quality of devices, are only some of the important factors that decide the level of use of m-commerce, and consequently, the level of its development [15].

The purpose of designing interfaces for mobile applications should be to increase consumers' interest in using and dedication to $\mathrm{m}$-commerce. Among the inhibiting factors is that $\mathrm{m}$-commerce applications were developed based on ecommerce applications. The most important thing when designing such applications is to design the application in such a way that it does not distract the user from the main purpose of the application [15]. However, aspects concerning security and accessibility should not be neglected. Even though storing sensitive data such as medical, financial, or personal information on mobile devices can help people, the risks of losing such information or of unauthorized access are higher and should be considered when an m-commerce transaction begins[16].

This paper will review the latest trends in mobile and ecommerce applications and will develop an application architecture that describes the internal architecture of both web and mobile components. Moreover, the focus will be on developing a more sophisticated demonstration mobile application regime that will employ web-services to communicate with web servers. Furthermore this paper will discuss the main characteristics of devices used for $\mathrm{m}$ commerce, the available survey design guidelines, and the important role of these characteristics for increasing the potential of m-commerce will be articulated.

This paper will also investigate the requirements of ecommerce applications and why normal websites are not suitable for mobile devices. More specifically this paper will analyse the characteristics required for websites so that they function properly on mobile devices. These characteristics are screen size, input device, task-based interfaces for mobile devices, m-loyalty, design aesthetics and website design. Other research questions relate to the reason why mobile native applications are preferred over mobile websites and 
what can be achieved using PhoneGap cross-mobile platform applications. Finally, the paper will attempt to provide solutions for mobile application development and make recommendations for future directions.

\section{RESEARCH METHODOLOGY}

A literature review on the two major issues of e-commerce mobile applications has been conducted, these being: firstly, the interface usability of mobile applications; and secondly, design and security considerations. The literature review concluded that mobile applications must effectively operate on different Smartphones and have the ability to use different ecommerce web applications through web services.

\section{A. Research Procedure}

The main question answered here is: "How can we exploit the usability and security of e-commerce application(s) for mobile devices (m-commerce) with maximized mobile platform independence?"

The sub-questions indicated below should be answered in order to fully explain the main themes in this paper :

1) Why is mobility required for e-commerce application?

2) Why are normal websites not useful for mobile devices?

3) Why are mobile native applications preferred over mobile websites?

4) What can we achieve using the PhoneGap (cross-mobile platform application development framework)?

5) How will the initial application architecture use Spreecommerce, PhoneGap and web applications?

6) What are the different solutions for developing mobile applications?

In this paper the focus was also on developing a prototype mobile application. The following steps were taken in order to complete a demonstration application:

1) Understanding how the Spree commerce system was developed and how it works.

2) Improved the application architecture based on more research and actual development experience gained while developing the application.

3) Developed a more sophisticated demonstration mobile application that will communicate with web servers through web services.

a) Developed of the PhoneGap application and tested it on iOS and Android

Page constraints have limited the paper's scope to actual functionality of the application. This paper will therefore discuss basic functionality.

Step 1: In order to achieve the first goal based on the web server was set up a Spree-commerce Ruby on Rails application. Spree is basically an open source e-commerce system and it has the ability to deal with web services in obtaining a list of products, product details and cart system.

Step 2: A mobile application gap via PhoneGap (mobile application development framework). Then product listing and view page was initiated through managing data from web services

Step 3: The application was tested on different Smartphones as follow:

1) Test on iPhone Simulator

2) Test on iPad Simulator

3) Test on Android Simulator

4) Test on actual iPhone device by paying 100\$ apple developer account

\section{B. Software development methodology}

Based on the questions developed for this study a general search was conducted in the first phase of the research. Software architecture was developed based on this research. The results of the research enabled the initial scope of the research to be more precise and achievable. Various software development methodologies were utilized since software engineering is a diverse field and encompasses many diverse factors and contexts. Experimental software engineering was used in the initial development phase so that risk and uncertainty were reduced. An iterative software model was used as it is the best choice for prototype development.

\section{Application Architecture}

The application architecture is explained in terms of how: the Spree web application is hosted on the Ruby on Rails equipped webserver. Web services have been built inside the Spree application; and the mobile phone native applications built using PhoneGap which communicates with the webserver through web services to obtain data and information. (Figure1). This diagram shows how the application architecture used the Spree web server and a native mobile application using PhoneGap which allows the same application to run in different mobile operating systems. This corresponds with the web server which uses web services to obtain data.

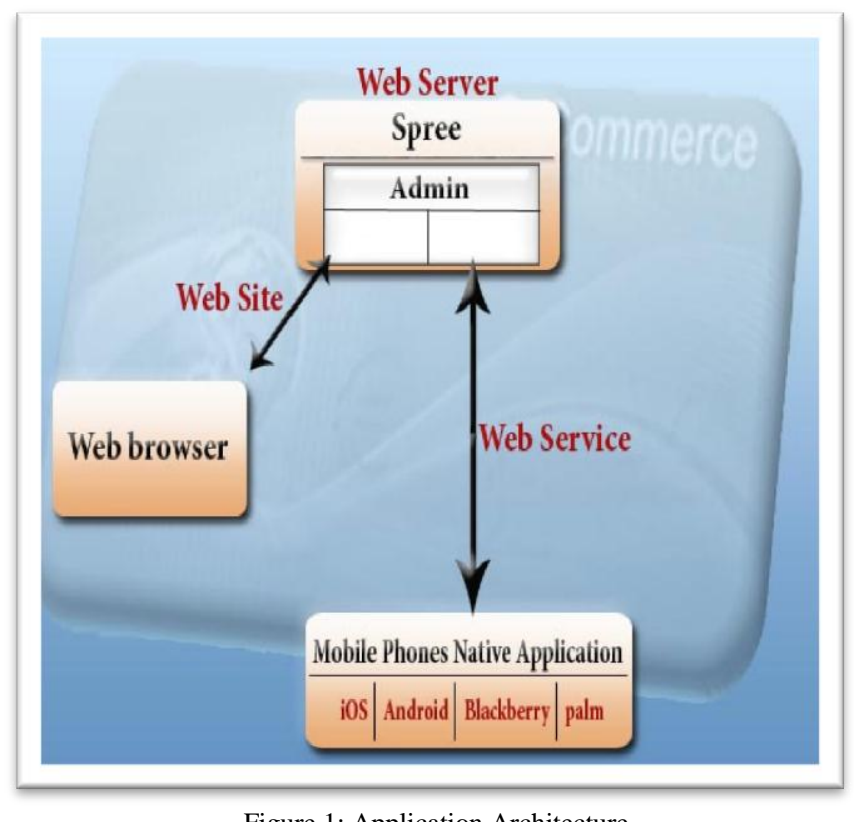

Figure 1: Application Architecture 


\section{SCOPE}

\section{A. Scope of application}

The basic functionality delivered by the application features two main factors, product listing and a product detail page.

Two changes were made,

- Spree web services were modified in order to show complete data in our mobile application.

- The functionality needed so that the mobile application can list products by requesting web services provided by the Spree-commerce application was added.

- The functionality of the mobile application was improved to show complete information on a product by requesting a second web-service from the Spree-commerce application.

Best practices were employed for making the user interface of the mobile application functional.

\section{RESULT}

\section{A. User/System scenario}

- The process starts when a user starts the mobile application.

- The mobile application requests the product listing web service.

- The web application (Spree-commerce application), which operates on remote web servers receives product listing web service requests.

- The web application finds the published products from the database and prepares JSON response.

- The mobile application receives JSON response and will convert it into HTML and render it. The mobile application also makes sure that all links in the product list should only work as AJAX.

- When the user selects a product the mobile application sends on AJAX request to the server for the product details web service.

- The server finds full details of the product and sends JSON response.

- The mobile application prepares HTML from JSON response for the display on the screen.

\section{B. $\quad$ iOS and Android Demo Application}

The application was tested on Android and iOS (iPhone/iPad/iPod operating system). The application provided two web services. Figures 2 and 4 depict the web service which enables the user to see a list of products available. Figure 3 shows that when you tap (select) any of these products, a new detailed page relating to the product selected will open and display information such as image, colour and price.

\section{1) iPhone simulator tested}

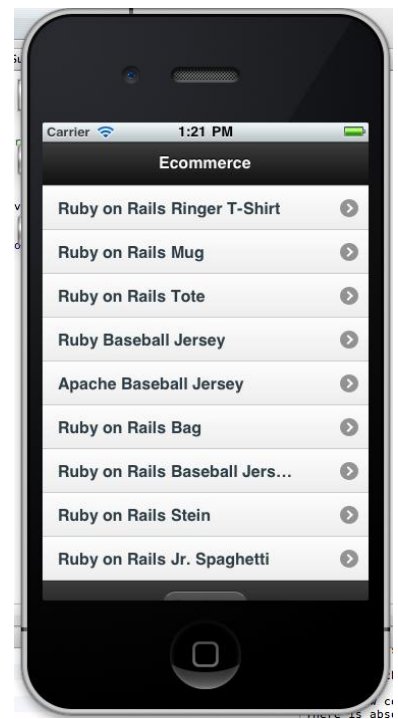

Figure 2: List of products on iPhone

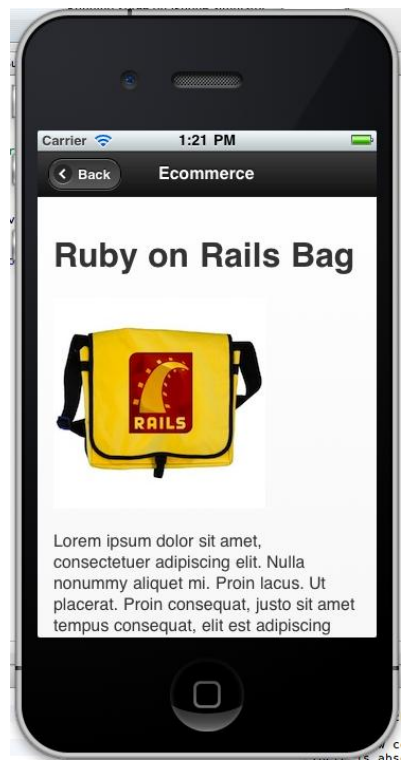

Figure 3: Product detail screen on iPhone

2) Android simulator tested

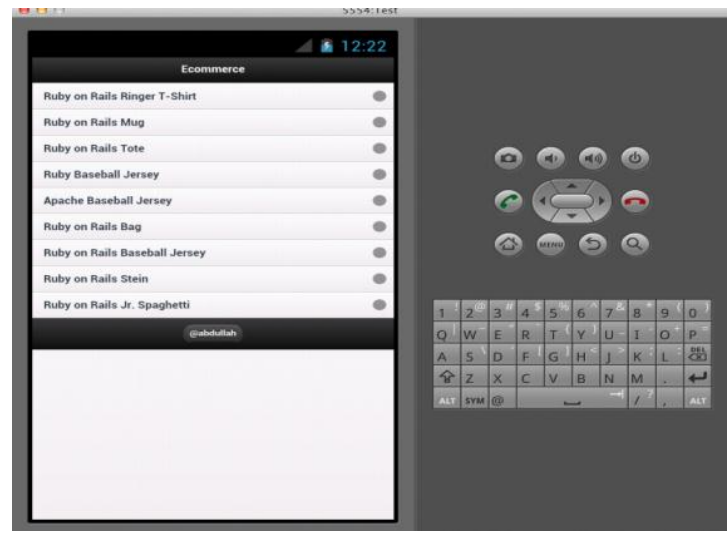

Figure 4: List of products on Android 


\section{SET UP AND SETTING UP}

A. Setting up Spree web application

1) Before starting the Spree application the following applications must be installed:

a) Unix bases $O S$

b) Mysql5

c) Ruby 1.8 .7 or 1.9 .2

d) Ruby on Rails 3.0.9

e) ImageMagick (library for image processing; used for generating different sizes of images)

2) Once these applications are installed then the following steps are needed:

a) Copy the ecommerce application code. folder

b) On UNIX terminal go to ecommerce application

c) Run bundle install [Make sure machine is connected to internet because this command will install all dependencies for the application]

d) rake db: create [ It will create MYSQL database]

e) rake $d b$ : migrate [ It will create all tables]

f) rake db: bootstrap [ It will load sample data in database]

g) Rails $S$ [ run web application server]

h) Use frontend and admin panel of Spree application for exploration

\section{B. Mobile applications}

1) Deploy to $\mathrm{iOS}$ : project

a) Run Xcode and open iOS version of PhoneGap

b) Deploy to actual iOS device

- Add your device to apple provisioning portal (remember paid developer account is needed)

- $\quad$ Select device to be used in execution list and Click run button

c) Or run on iPhone simulator

- Select iPhone simulator in execution list and click run button

2) Deploy to Android:

a) Download and install Eclipse Classic.

b) Download and install Android SDK..

c) Download and install ADT Plugin for Eclipse.

d) Download the latest copy of PhoneGap and extract its contents.

e) Setup Project.

f) Merge our HTML code to be I used.

\section{DISCUSSION RESULT}

E-commerce functionality was provided by installing a Spree application on a web server. The research suggested that mobile phones such as Android-based Smartphones, iPad and
iPhones were appropriate for installing the PhoneGap application on them. The research also illustrated that using JSON-based web services promoted data communication between PhoneGap and the Spree application. The native support of JSON in JavaScript and it being comparatively lightweight was the significant reason why this report suggested JSON should be selected instead of the XML data format.

The actual Spree application provided several web services but the research forewarned that these web services would not be feasible with every application. For instance, often there was too much unneeded information on a products listing web service. For this reason and that of network latency, not only did an application slow down but in response to the JSON object. The processing of JSON in JavaScript was increased. The research also suggested that the required data such as the ID, title, the short description and slug were obtained by overriding that particular web service.

As the research elaborated, depending on the screen size of mobile phones, it was often the case that image sizes for the Spree application were either too large or too small. Fortunately, the paperclip library that is available in the Spree application was able to regenerate all the images after their smaller sizes were introduced. The research also suggested that for the UI components of a Smartphone, jQuery and jQueryMobile should be employed. The research also illustrated the fact that no image was used for UI components but rather CSS3 features were used, making this library the preferred option. The research indicated that jQuery guidelines were used to create a robust code and jQunit, which is a jQuery-based unit testing library dedicated to unit testing.

According to the research a PhoneGap template was used to make an Xcode project once this functionality became functional on WebKit based browsers such as Chrome and Safari. CSS, HTML and JavaScript were embedded into this project template. The research suggested that iPhone and iPad simulators had to be used for testing until it was definite that they worked appropriately. Once they indeed worked appropriately, the application was then tested on the actual device by purchasing a $\$ 100$ Apple developer account.

The research highlighted the fact that Android Smartphones followed a similar process. Android development and the Eclipse IDE plug-ins had to be installed in this case. The research suggested that an Android template was then used to make an eclipse project, merging CSS, HTML and JavaScript into the template as well. Ultimately, the research indicated that the Android simulator had to be utilized to compile and test the application. This was the process used to execute the application and ensure its success.

\section{CONCLUSION AND FUTURE DIRECTIONS}

Mobility of people and technologies are key factors in today's economy. Mobile applications are of utmost importance when companies market their products or services. Mobile phones have generated an incredible opportunity for accessing the Internet, while $\mathrm{m}$-commerce has increased the level of using a mobile phone for business. Applications for electronic and mobile commerce are, however, developed 
sufficiently to cover all aspects of the market. The ideal applications do not distract the user from his/her intent and they provide on appropriately level of security, accessibility and speed. Screen size, input device, urgency, task based interfaces, and design are important aspects that developers have to consider when designing mobile phone applications. Such applications should be implemented on different operating systems, whether using JavaScript, CSS3 or HTML5, or combining these three together. The installation of a Spree application allows partial web services to function because not all applications may work with these web services. The device screen size proved to be of great importance but the Spree application solved these issues. Simulators for iPhone and iPad represent an excellent way to test applications.

\section{A. Future directions}

In order to bring this research from its current analysis on the basic model to an advanced level, the points listed under the scope of excluded and discussed below must also considered.

Payment transactions need to be made through a more secure and safe channel like Pay-Pal, which will ensure a safe and sound transaction system. Transaction payments should be password protected or should have a PIN code that confirms its reliability. Even if the gadget used - for example a cell phone - is lost, stolen or otherwise incapable of being used, consumers would not have to worry about theft or mismanagement of money. Furthermore, they can obtain a password to improve protection and security.

Products listed on the product information pages should have paged display pictures, which will be more appealing to the viewer. The product should be listed with information such as the product specifications: price, part number, technical details, features and packaging details. Yet some product information pages do not provide this information which is very inconvenient for the consumer and does not present a professional image.

The applications should allow users to change the web services' URLs. Settings should be made flexible so that users can improvise and access the web services they require by changing settings. The application should allow the user to add multiple sources for the same web server by cell phone so that the user can code flex, which means that a user can develop and deploy cross-platform Internet applications being run on cell phones. This implies that a mobile application should be able to locate a list of products from different remote applications, which provide the same web services being supported by a mobile application.

\section{REFERENCES}

[1] Ngai, E.W.T. \& A. Gunasekaran (2007). A review for mobile commerce research and applications. Decision Support Systems, vol. 43, no. 1, pp. 3-15.

[2] Cyr, D., M. Head \& A. Ivanov (2006). Design aesthetics leading to mloyalty in mobile commerce. Information \& Management, vol. 43, no. 8, pp. $950-963$.

[3] [Sumita, Ushio \& Jun Yoshii (2010). Enhancement of e-commerce via mobile accesses to the Internet. Electronic Commerce Research and Applications, vol. 9, pp. 217-227.
[4] Lee, Ching-Chang, Hsing Kenneth Cheng \& Hui-Hsin Cheng (2007). An empirical study of mobile commerce in insurance industry: Tasktechnology fit and individual differences. Science Direct, vol. 43, 2007, pp.95-110.

[5] Wu, Jen-Her \& Yu-Min Wang (2006). Development of a tool for selecting mobile shopping site: A customer perspective. Science Direct, vol. 5, pp. 192-200.

[6] Wu, Jen-Her \& Shu-Ching Wanga (2005). What drives mobile commerce? An empirical evaluation of the revised technology acceptance model. Information \& Management, vol. 42, pp. 719-729.

[7] Yung-Ming, Li \& Yung-Shao Yeh (2010). Increasing trust in mobile commerce through design aesthetics. Computers in Human Behavior, vol. 26, pp. 673-684.

[8] Chang, Yung-Fu \& C.S. Chen (2005). Smart phone- the choice of client platform for mobile commerce. Computer Standards \& Interfaces, vol. 27, pp. 329-336.

[9] Barnes, Stuart \& Eusebio Scornavacca (2007). Chapter 7: The emergence of mobile commerce. In Stuart Barnes, E-Commerce and $V$ Business: Digital Enterprise in the Twenty-First Century, $2^{\text {nd }}$ ed. Oxford, U.K.: Butterworth-Heinemann, pp. 157-178.

[10] Lehtinen, Toni (2011). Native versus Web - which approach is best for mobile apps?, mobilesolutions, White Paper, 2011, pp. 2-6.

[11] Power, Mark (2011). Mobile Web Apps: A Briefing Paper. Centre for Educational Technology \& Interoperability Standards, March. Mark Power@CETIS.

[12] Descartes (2010). Why PhoneGap, 4p., Descartes website. Retrieved July 28, 2011 from http://www.phonegapmobileappdev.com/wpcontent/uploads/Why-PhoneGap.pdf.

[13] Soriano, M. \& D. Ponce (2002). A security and usability proposal for mobile electronic commerce. Communications Magazine, vol. 40, no. 8, pp. 62-67.

[14] Buranatrived, J. \& P. Vickers, P (2002). An investigation of the impact of mobile phone and PDA interfaces on the usability of mobilecommerce applications. Proceedings of the IEEE 5th International Workshop on Networked Appliances. Liverpool: pp. 90-95.

[15] Koukia, Spiridoula, Maria Rigou \& Spiros Sirmakessis (2006). The Role of Context in m-Commerce and the Personalization Dimension. In International Conference on Web Intelligence and Intelligent Agent Technology Workshops, 2006. WI-IAT 2006 Workshops. Hong Kong: pp. 267-276.

[16] Leavitt, N. (2010). Payment Applications Make E-Commerce Mobile. Computer, vol. 43 , no. 12, pp. 19-22.

[17] Github Inc. (2011). Github Social Coding: spree, Github Social Coding website. Retrieved Jun 28, 2011 from https://github.com/spree/spree.

[18] Spree (n.d.). The World's Most Flexible E-Commerce Platform, Spree website. Retrieved August 3, 2011 from http://spreecommerce.com/.

[19] Nitobi (2011). Home page, PhoneGap website. Retrieved August 20, 2011 from http://www.phonegap.com/.

[20] Kurvosky, Stan, Vladimir Zanev \& Anatoly Kurkovsky (2005). SMMART: using context-awareness in m-commerce. In MobileHCI '05: Proceedings of the 7th International Conference on Human Computer Interaction with Mobile Services \& Devices. New York: ACM, pp. 383384.

[21] PocketHacks.com (2011). iOS page, All about Windows Mobile, Windows Phone 7 and Android devices, latest news, freeware apps and hacks.. Retrieved August 20, 2011 from http://pockethacks.com/ios/.

[22] ImageMagick Studio LLC (2011). About Imagemagick. Imagemagick.org website. Retrieved October 5, 2011 from http://www.imagemagick.org/script/index.php.

[23] Nitobi (2011). How PhoneGap Works. PhoneGap website. Retrieved August 20, 2011 from http://www.phonegap.com/about.

[24] TechTerms.com (2010). Android. TechTerms website. Retrieved September 17, 2011 from http://www.techterms.com/definition/android.

[25] PC Magazine (2011). Definition of AJaX. PC Magazine website. Retrieved August 11, 2011 from http://www.pcmag.com/encyclopedia_term/0,2542,t=AJaX\&i=55346,00 .asp\#fbid=cGwEB1ODoJ 6 .

[26] The jQuery Project (2011). Homepage, jQuery Mobile Framework website. Retrieved September 5, 2011 from http://jquerymobile.com/.

[27] Internet.com. (2011). jQuery, in Webopedia website. Retrieved

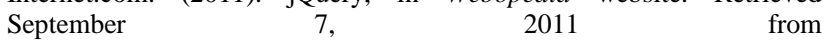
http://www.webopedia.com/TERM/J/jQuery.html. 
[28] About.com (2011). JSON: JavaScript Object Notation, About.com website. Retrieved August 3, 2011 from http://javascript.about.com/library/bljson.htm.

[29] Motive Ltd. (2010). The Motive Internet Glossary: MySQL. Motive Glossary website. Retrieved August 3, 2011 by http://www.motive.co.nz/glossary/mysql.php.
[30] Howard, Alexander B. (2006). Definition: Ruby on Rails (RoR or Rails), SearchSOA.com website. Retrieved July 3, 2011 from $\mathrm{http} / / /$ searchsoa.techtarget.com/definition/Ruby-on-Rails.

[31] Linux Information Project (2005). Unix-like Definition [updated June 18, 2006], Linfo website. Retrieved July 1, 2011 from http://www.linfo.org/unix-like.html. 